\title{
Systematic review and meta-analysis of the most common processed foods consumed by Iranian children
}

Mina Babashahi, ${ }^{1}$ Nasrin Omidvar, ${ }^{1}$ Bahareh Yazdizadeh, ${ }^{2}$ Motahar Heidari-Beni, ${ }^{3}$ Hassan Joulaei, ${ }^{4}$ Saba Narmcheshm, ${ }^{5,6}$ Azizollaah Zargaraan ${ }^{7}$ and Roya Kelishadi ${ }^{3}$

${ }^{1}$ Department of Community Nutrition, National Nutrition and Food Technology Research Institute, Faculty of Nutrition Sciences and Food Technology, Shahid Beheshti University of Medical Sciences, Tehran, Islamic Republic of Iran (Correspondence to: N. Omidvar: omidvar.nasrin@gmail.com). ${ }^{2}$ Knowledge Utilization Research Center, Tehran University of Medical Sciences, Tehran, Islamic Republic of Iran. ${ }^{3}$ Department of Pediatrics, Child Growth and Development Research Center, Research Institute for Primordial Prevention of Non-Communicable Disease, Isfahan University of Medical Sciences, Isfahan, Islamic Republic of Iran. ${ }^{4}$ Health Policy Research Center, Institute of Health, Shiraz University of Medical Sciences, Shiraz, Islamic Republic of Iran. ${ }^{5}$ Students' Scientific Research Center, Tehran University of Medical Sciences, Tehran, Islamic Republic of Iran. ${ }^{6}$ Department of Community Nutrition, School of Nutritional Sciences and Dietetics, Tehran University of Medical Sciences, Tehran, Islamic Republic of Iran. ${ }^{7}$ Department of Food and Nutrition Policy and Planning Research, National Nutrition and Food Technology Research Institute, Faculty of Nutrition Sciences and Food Technology, Shahid Beheshti University of Medical Sciences, Tehran, Islamic Republic of Iran.

\begin{abstract}
Background: The trend of increasing overweight and obesity among children is a huge burden on health systems. In this regard, the growing availability of processed foods, often energy dense and nutrient poor, has become a major concern. Changing this trend will require evidence-based policies.

Aims: This systematic review aimed to identify the most common processed/ultraprocessed foods consumed by 4-12-yearold Iranian children.

Methods: We searched PubMed, Scopus and Web of science, as well as Persian scientific search engines, including Iran Research Information System, Scientific Information Database and Mag-Iran. We also assessed grey literature, that is, national studies and papers presented at relevant Iranian congresses. All data collected from studies were converted to daily servings (S/D). Mean and standard deviations of the included results were combined by performing meta-analysis with a random effects model. The $\mathrm{I}^{2}$ test was used to compute heterogeneity. Egger's test was used to assess publication bias.

Results: Ten studies with 67093 children were included in this review. The meta-analysis demonstrated that the highest consumption of processed foods belonged to the sugars and sweets group with 8.01 S/D, followed by oils, and biscuits and cakes with 5.58 S/D and 3.33 S/D, respectively.

Conclusion: Given the high consumption of less healthy processed foods, robust policies to support healthy eating and help improve Iranian children's food environment are recommended.

Keywords: processed food, ultraprocessed food, children, Islamic Republic of Iran, systematic review

Citation: Babashahi M; Omidvar N; Yazdizadeh B; Heidari-Beni M; Joulaei H; Narmcheshm S; et al. Systematic review and meta-analysis of the most common processed foods consumed by Iranian children. East Mediterr Health J. 2021;27(9):918-930. https://doi.org/10.26719/emhj.21.032

Received: 15/11/20; accepted: 01/03/21

Copyright (C) World Health Organization (WHO) 2021. Open Access. Some rights reserved. This work is available under the CC BY-NC-SA 3.0 IGO license (https://creativecommons.org/licenses/by-nc-sa/3.o/igo)
\end{abstract}

\section{Introduction}

Noncommunicable diseases (NCDs) are the major cause of morbidity and mortality in developing countries $(1,2)$. There is strong evidence of the association between childhood obesity and early onset of adult NCDs $(3,4)$. According to the World Health Organization, the global prevalence of childhood obesity has increased from 31 million children in 1990 to 42 million in 2013 (5). It is estimated that by 2025 , the prevalence of overweight in preschool children will increase to $11 \%$ worldwide (6). The Islamic Republic of Iran, as a middle-income country, is dealing with childhood overweight and obesity as a serious public health challenge $(7,8)$. The rate of overweight and obesity in Iranian children (aged 0-18 years) has increased from $5.5 \%$ in 2000 to $15.1 \%$ in 2013 (7). Moreover, a nationwide study in 2015 showed that $>20 \%$ of students aged 7-18 years had excess weight and abdominal obesity (9).
The consumption of processed foods (PFs) or ultraprocessed foods (UPFs) in children is a predisposing factor for childhood obesity and subsequent NCDs $(10,11)$. UPFs are energy dense with more fat, sugar and/ or sodium compared to fresh or minimally processed foods (10); therefore, their consumption can play a role in developing chronic diseases $(10,12)$ and obesity (13), as well as increased risk of metabolic syndrome and total and low-density lipoprotein-cholesterol concentrations $(14,15)$.

Children are a key target for marketing of UPFs (16) and their largest consumers in low- and middle-income countries (17). Children often have less control over their food environment and living in unhealthy food environments can encourage them to adopt low-quality food patterns (18). Therefore, reducing their exposure to food marketing is an important prevention strategy for obesity and NCDs (19). In the Islamic Republic of Iran over 
the past decade, advertising of unhealthy food products with high levels of saturated fat, sugar, salt and trans fatty acids has been banned (20). However, regulatory laws prohibiting advertisements have been passed for the general population, with little reference to children (20). Additionally, there is a ban on food marketing and advertising in kindergartens and schools (21). However, 3 studies in Kerman, Tabriz and Tehran have shown that schools do not completely control unhealthy food advertisements in their environment (22-24). Since 2014, attempts have been made to improve school food environment through national school canteen regulations to increase access to healthy snacks and prevent the supply of foods with low nutritional value (25). Despite several years of implementation of this bylaw, $>50 \%$ of food items available in school canteens do not comply with the permitted food lists $(23,24)$. Insufficient physical and economic infrastructure, inadequate monitoring, conflict of interest due to financial profitability of selling unhealthy food, high price of healthy foods, and shortage of healthy food alternatives are the main causes of incomplete implementation of the policy $(23,24)$. Other programmes, such as provision of school milk, are examples of attempts to promote healthy foods for children in the Islamic Republic of Iran (26), which have had little success due to poor infrastructure and implementation (27-29).

Therefore, there is a need to upgrade existing policies or develop coherent and sustainable ones that can support a healthy food environment and ultimately benefit children's health $(1,13)$. In this regard, lack of evidence on the status of children's food consumption, specifically with regard to PFs/UPFs is an issue. To our knowledge, there is no clear estimate of consumption of PFs in Iranian children, and previous studies have shown conflicting results. To fill this gap, this study aimed to systematically review the literature regarding the consumption of PF products in Iranian children aged 4-12 years.

\section{Methods}

The protocol of this systematic review was registered at http://www.crd.york.ac.uk/PROSPERO/ as CRD42019134151. The study was reported in accordance with the PRISMA guidelines (Preferred Reporting Items for Systematic Reviews and Meta-Analyses) (30). The PO (population, outcome) criteria were used to formulate the review question $(31,32)$. Population characteristics included healthy Iranian children aged 4-12 years, and the outcome component referred to the type and amount of consumption of PFs or UPFs.

\section{Inclusion and exclusion criteria}

The inclusion criteria to select articles for analysis were: cross-sectional and case-control studies that surveyed type and amount of PFs consumed by Iranian children aged 4-12 years. Consumption was reported as intake amount or frequency of intake of food items. Therefore, studies that reported other consumption units, such as the percentage of students who consumed food items, or presented $\geq 2$ PFs together as a food group, were excluded.

NOVA (a name, not an acronym) system is a strategy for categorizing foods according to their degree of processing (33). According to the NOVA food framework, PFs are defined convenient or packaged foods that are commercially prepared to optimize ease of consumption (33). Most PFs contain 2 or 3 ingredients such as sugar, oil and salt (34). UPFs contain at least 1 item characteristic of the NOVA UPF group, including food substances never or rarely used in kitchens (e.g., hydrolysed proteins or highfructose corn syrup), or cosmetic additives that make the final food product more delicious or pleasing (e.g., colours, foaming, flavours, emulsifiers, and carbonating agents) (34). Due to the limited access to information on ingredients of food items in the included studies, it was impossible to distinguish between PFs and UPFs. Therefore, we used the term PF to cover both. Studies that included individuals with the defined age range of 4-12 years were not considered for this review, unless extracting related data about this age range was possible. Only healthy children were included in the review and children with specific diseases such as diabetes or coeliac disease were excluded. We included studies conducted in the Islamic Republic of Iran in various settings, including community and schools, without any restriction on race, education level and socioeconomic status. Qualitative studies, commentaries, letters, or editorial were not included.

\section{Search strategy}

Electronic databases, including PubMed, Scopus and Web of Science, and 3 Persian scientific search engines, Iran Research Information System (www.idml.research. ac.ir), Scientific Information Database (SID: www.sid. ir) and MagIran (www.magiran.com), were searched systematically. We also searched proceedings of child and nutrition-related congresses in the Islamic Republic of Iran and national studies (grey literature), as well as reference lists of included articles. Studies were selected without language restriction.

Key words were obtained from MeSH, Emtree, suggestions of experts, or extracted from related articles. The study syntax was formed from 3 components that combined together with the AND operator. The first component referred to all PF items that were searched together by operator OR and the following keywords: processed food, ultra-processed foods, packaged food, packed food, industrial food, prepared food, junk food, energy-dense foods, nutrient-poor foods, low-nutrientdensity foods, fast food, snack, snack food, unhealthy snack, sweet snack, salty snack, savoury snack, carbonated beverage, carbonated drinks, soft drink, soft beverage, soda, nonalcoholic beverage, noncarbonated beverage, sugar-sweetened beverage, industrial juice, industrial fruit juice, unnatural juice, packaged fruit juice, unnatural juice, syrup, compote, preserves, jam, cooked fruit, canned food, milk, flavored milk, chocolate 
milk, milk cacao, potato chips, fried potato, French fries, chips, potato crisps, puffed corn, puffs, Cheetos, cheese puffs, cheese curls, cheese balls, cheesy puffs, corn curls, corn cheese, Mexican corn, pretzels, chocolate, candy, cacao, sweets, confectionary, pastries, pie, pudding, cheesecake, baked desserts, doughnut, donuts, cake, industrial cake, cupcake, muffin, cookies, biscuit, cracker, wafers, Gaz, Sohan, Noghl, sandwiches, hamburger, sausage, bologna, bologna sausage, hot dog, cold cut, nugget, ham, pizza, Olivier salad, Russian salad, falafel, samosa, noodle, popsicles, freezer pop, ice pop, ice lolly, ice cream, tamarind, fruit strips, fruit roll, gum, chewing gum, pastilles, dragee, gelatin dragee, taffy, toffy, toffee, pickles, salty cucumber, salty nuts, salted nuts, Nutella, sauce, mayonnaise, ketchup, candies, sugar confectionary, marshmallows, smarties, puff pastry, sugars, Nabat, bologna sausage, bologna, freezer pop, fruit leather, jellies, gelatin dessert, jelly, breakfast cereal, cornflakes, butter, cream, tea-bag, coffee mix, bread, baguette bread, toast, spaghetti, macaroni, pasta, vermicelli, Kashk, caramel cream, Danette, dough, yogurt, yoghurt, cheese, oil, non-alcoholic beer, alcohol-free beer. Two other components included Iran as the study location and date of publication (1 January 1990 to 1 January 2019).

\section{Article screening and study selection}

Two of the authors (MB and SN) independently conducted the stages of screening and study selection. Any disagreement between them was resolved through consensus, and if disagreement was not resolved, a third opinion was sought (NO). In primary screening, the title and abstract of collected studies were reviewed according to the inclusion and exclusion criteria. In the second phase of screening, full texts of the articles were evaluated. In the case of missing data in the included studies, authors were contacted to access and complete data. If we could not gain access to sufficient data after sending 3 emails over 6 weeks, the study was eliminated from the data synthesis process. We included the data from a national survey of weight disorders (35). Since we had access to the data from this national study, articles derived from it were excluded.

\section{Quality assessment}

Two reviewers independently assessed the quality of included studies and disagreements were resolved through consensus. The corresponding author was also consulted whenever necessary. The quality of studies was assessed by the Newcastle-Ottawa Quality Assessment Scale (NOS) $(36,37)$. Based on NOS, case-control studies were scored from 1 to 9 points on 3 items: case and control group selection, comparability of groups, and assessment of the exposure. Also, cross-sectional studies were scored for sample selection (representativeness of the sample, sample size, nonrespondents, and ascertainment of the exposure), comparability of the subjects (adjustment for confounders), and assessment of the outcome (using validated tool or method and statistical analysis). Each cross-sectional study could receive a maximum score of
10. Studies were considered as unsatisfactory (score $<4$ ), satisfactory (5 or 6), good (7 or 8), and very good (9 or 10 ).

\section{Data extraction}

From each of the included studies, the following information was recorded in the data extraction table: first author's name, year of publication, study city/province of study, study setting (school or health centre), study design (cross-sectional or case-control), participant characteristics (age and sex), data collection method, type of processed food items, and quantitative data [sample size, means and standard deviations (SDs) of the amount or frequency of food intake and units of consumption]. In case-control studies, only the control group's data were extracted, which were related to healthy children.

\section{Data analysis}

PF items were categorized into 7 groups based on the new Iranian food pyramid (38). Seven food groups are presented in 4 layers from bottom to top: bread and cereals; fruit and vegetables; meats and eggs, milk and dairy products, nuts and legumes; and miscellaneous, consisting of fats and sugar. After completing the data extraction table, the consumption data units were converted to mean daily intake (g/day) and then to daily servings. For reporting the total servings of each food group, the mean value and standard deviation of daily servings of consumption between two or more food items were pooled. The value of the standardized mean difference (SMD) using means and SDs of $\mathrm{n}$ groups were calculated as follows:

$$
\begin{gathered}
\text { Cohen's } d=\text { Mean }_{1}-\text { Mean }_{2} \ldots-\text { Mean }_{\mathrm{n}} / \text { SD pooled } \\
\text { SD pooled }=\sqrt{ }\left[\left(\left(\mathrm{s}_{1}\right)^{2}+\left(\mathrm{s}_{2}\right)^{2} \ldots+\left(\mathrm{s}_{\mathrm{n}}\right)^{2}\right) / \mathrm{n}\right]
\end{gathered}
$$

Meta-analysis was performed for each food group, which was reported in at least 3 studies. The metaprop command in Stata (version 14) was run to calculate the pooled serving intake of PFs in Iranian children. Metaanalysis and subgroup analysis were performed by using random-effects inverse-variance weights.

$\mathrm{I}^{2}$ statistical index was used for assessment of study heterogeneity. Interaction test $\left(\chi^{2}\right)$ was conducted to compare subgroups by repeating subgroup analyses under the fixed-effects model. If a meta-analysis included $>3$ studies, publication bias was estimated based on Egger's regression test (39), and $\mathrm{P}<0.05$ was considered indicative of statistically significant publication bias.

\section{Ethical considerations}

The study protocol was approved by the National $\mathrm{Nu}$ trition and Food Technology Research Institute's Ethics Committee and received the ethic code: IR.SBMU.NNFTRI.REC.1397.035.

\section{Results}

As shown in the PRISMA diagram (Figure 1), out of 67093 studies identified by searching databases and grey literature, 10373 were excluded after removing duplicates. The title and abstract of 56720 studies were screened based 


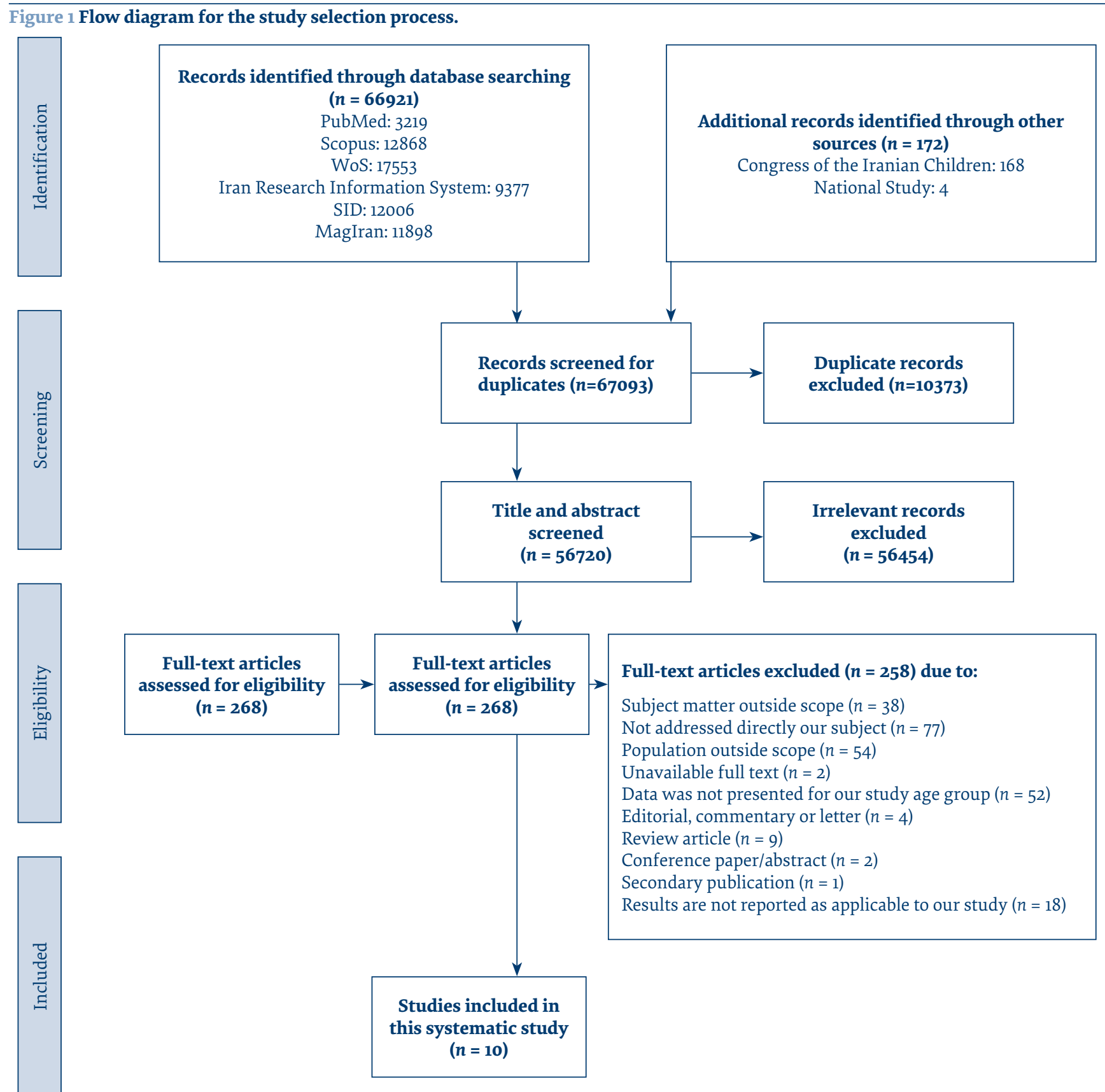

on the inclusion criteria, and 56454 irrelevant studies were removed. Two studies were identified through hand searching of included studies' references and added to the full-text screening stage. Finally, of 268 full texts evaluated, 10 were eligible for inclusion. The characteristics of the included studies and the result of their quality assessment are presented in Table 1 . The quality assessment of studies showed that 2, 3, 4 and 1 studies had very good, good, satisfactory, and unsatisfactory quality, respectively. Five studies reported food items in the bread and cereals group (35,40-43), 6 reported food items in the fruit group (35,40,42-45), 4 studies reported food items in the vegetable group $(35,40,41,43), 5$ studies reported food items in the meat group $(35,40,42,43,45), 5$ studies included food items in the nuts and legumes group (40,42-45), 5 studies included food items in the milk and dairy group
$(35,40,41,43,46)$ and 9 studies reported food items in the miscellaneous group $(35,40-45,47,48)$. Mean daily servings are shown in Table 2.

Based on the meta-analysis (Table 3), the highestlevel consumption was for sugar and sweets (8.01 daily servings), oil (5.58 daily servings), biscuits and cakes (3.33 daily servings) and bread items (2.90 daily servings). There was substantial heterogeneity for soft drinks $\left(\mathrm{I}^{2}=\right.$ $71.0 \% ; P=0.004)$ and a considerable heterogeneity for the other food items that reported in the minimum required number of studies for analysis $\left(\mathrm{I}^{2}>94.00 \% ; \mathrm{P} \leq 0.004\right)$. Publication bias evaluated by Egger's regression test was considerable for bread, milk, ice cream, puffs and chips, and soft drinks $(P<0.05)$.

Subgroup analysis for sex and data obtained from forest plots are summarized in Table 4. Based 


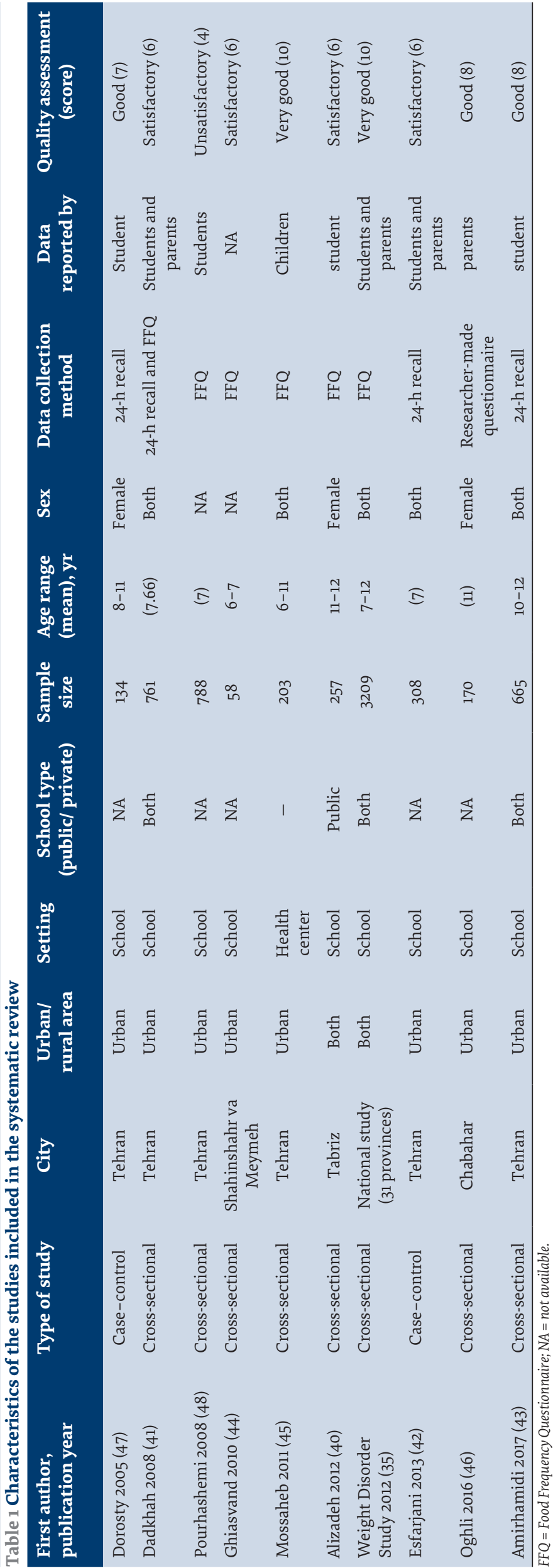

on subgroup analysis, consumption of soft drinks and pickles was higher in boys (0.18 and 0.48 daily servings, respectively) compared with girls (0.15 and 0.17 daily servings, respectively). In contrast, girls had significantly higher consumption of macaroni and pasta, processed meat, milk, milk with added sugar, yogurt, ice cream, sugar and sweets, puffs and chips, butter, coffee, and sauce $(P<0.001)$.

\section{Discussion}

This systematic review demonstrated that the highest consumption of PFs among 4-12-year-old children in the Islamic Republic of Iran was for sugar and sweets followed by oils, biscuits and cake, and bread. Iranian children have a high consumption of miscellaneous food groups, which does not correspond with the current recommendations. The Iranian food guide emphasizes reducing consumption of sugar-sweetened foods and beverages and soft drinks as low as possible (43). The findings endorse previous qualitative reports regarding the high consumption of junk foods, especially in children and adolescents in the Islamic Republic of Iran (49).

High consumption of energy-dense nutrient-poor foods, e.g., candies, sweets, biscuits, cakes, and cookies, has also been reported in children of other countries $(14,50-53)$. Bread, candy, savoury snacks, cookies and other sweets were the main PFs and UPFs consumed by Brazilian children (14). A dietary survey in the United Kingdom of Great Britain and Northern Ireland showed that a small percentage of children followed the recommended daily intake of free sugar (51). Cereals and cereal products (33\%), sugar, preserves and confectionery $(23 \%)$, and nonalcoholic beverages $(22 \%)$ were the main sources of free sugars in these children (51). A national health and nutrition survey in Mexico in 2012 also showed a higher energy contribution from UPFs among preschool children than other age groups, mainly due to high intake of ready-to-eat cereals, baby foods, juices and dairy drinks (53). According to a 2109 report by the United Nations Children's Fund on the state of the world's children, the diets of adolescents in low- and middle-income countries are nutritionally poor (50). Among school-going adolescents, $42 \%$ drink carbonated soft drinks at least once a day, while intake of fruit $(34 \%)$ and vegetables $(21 \%)$ is less than once a day $(50)$. Almost half $(46 \%)$ of children globally consume fast foods at least once a week (52).

The most important factors affecting this high consumption of nutrient-poor food items are availability, low price, media advertisements, and preference of fast food taste, diversity, attractiveness of packaging, inadequate awareness, and lifestyle changes $(49,54,55)$. Assessment of the food products advertised on 2 major Iran national television networks during children's television programmes showed that caloriedense foods, including chocolate, soft drinks, extruded cereals, ice cream, cookies and candies, were the most 


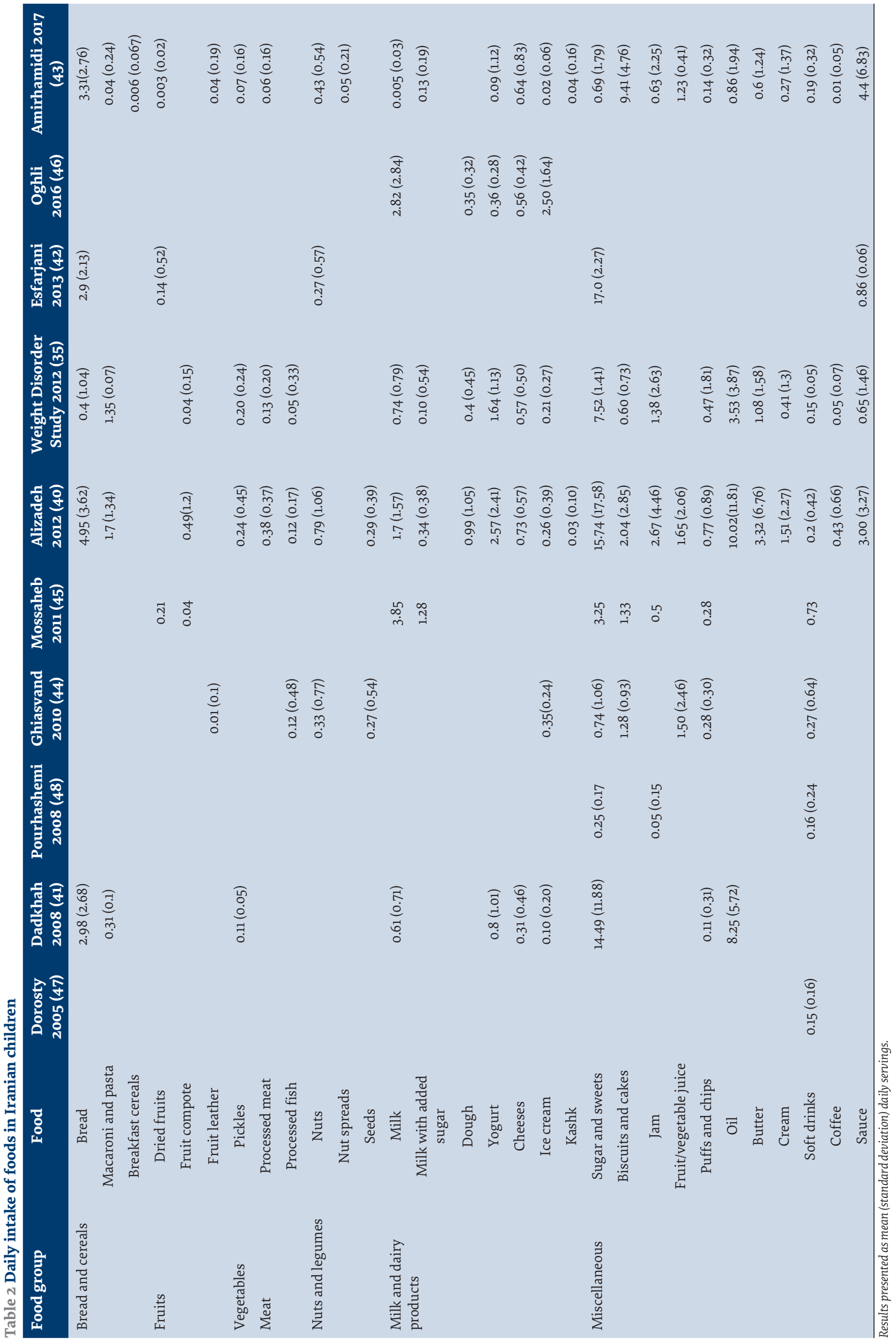




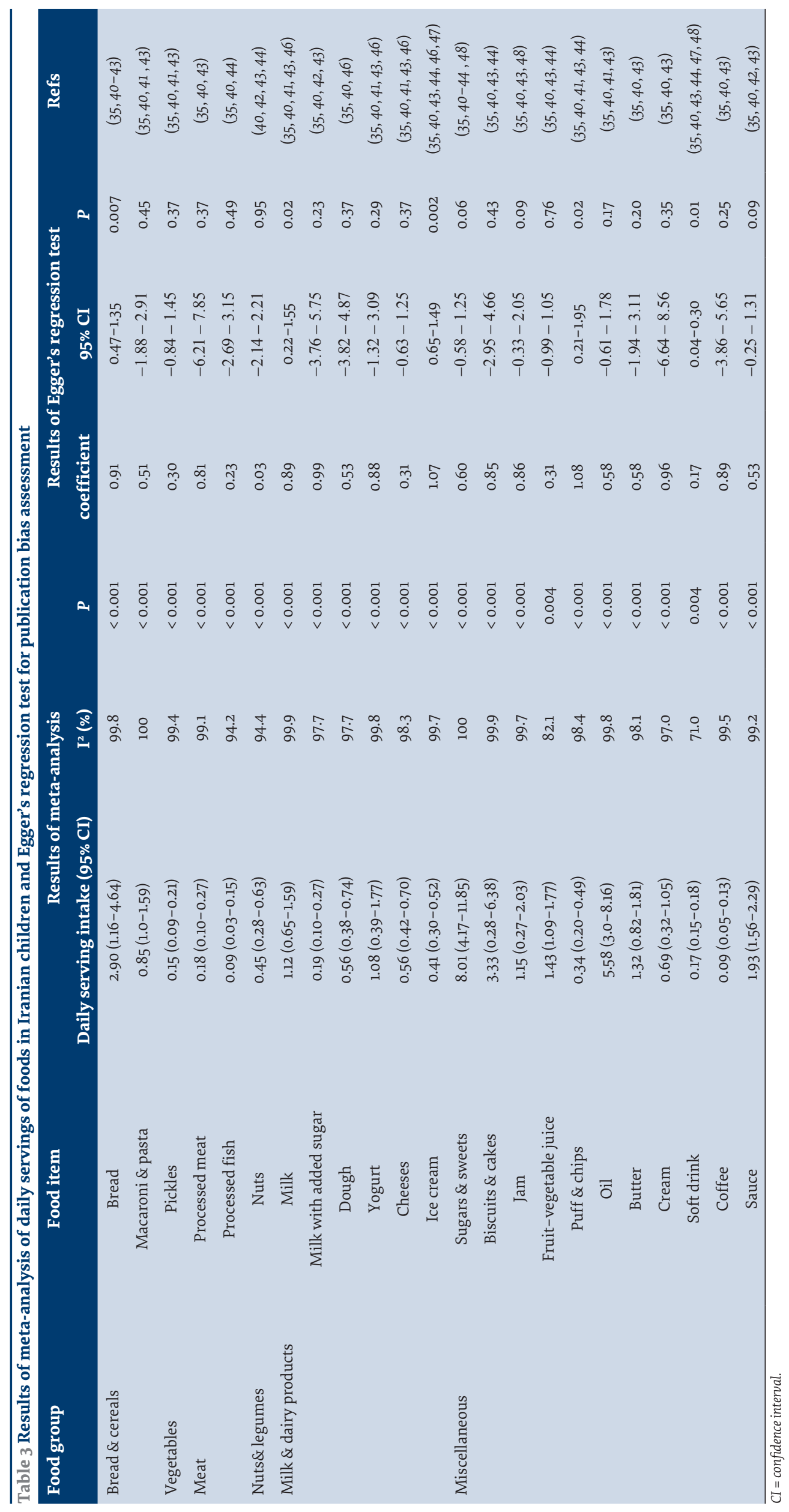




\begin{tabular}{|c|c|c|c|c|c|c|c|}
\hline Food group & Food item & $\begin{array}{l}\text { Subgroup } \\
\text { variable }\end{array}$ & $\begin{array}{l}\text { Daily serving intake } \\
\qquad(95 \% \mathrm{CI})\end{array}$ & $\mathrm{I}^{2}(\%)$ & $\mathbf{P}$ & $\begin{array}{c}\text { Interaction } \\
\text { test }\left(\chi^{2}\right)\end{array}$ & $\mathbf{P}$ \\
\hline \multirow[t]{6}{*}{ Bread \& cereals } & Bread & Girl & $2.77(0.12-5.42)$ & 99.7 & $<0.001$ & 1.72 & 0.190 \\
\hline & & Boy & $2.02(0-5.15)$ & 99.7 & $<0.001$ & & \\
\hline & & Overall & $2.39(1.85-2.92)$ & 99.6 & $<0.001$ & & \\
\hline & Macaroni \& pasta & Girl & $0.95(0.03-1.88)$ & 99.9 & $<0.001$ & 57.39 & $<0.001$ \\
\hline & & Boy & $0.54(0.00-1.55)$ & 99.9 & $<0.001$ & & \\
\hline & & Overall & $0.79(0.32-1.25)$ & 99.8 & $<0.001$ & & \\
\hline \multirow[t]{3}{*}{ Vegetables } & Pickles & Girl & $0.17(0.05-0.30)$ & 99.4 & $<0.001$ & $1.2 \times 10^{5}$ & $<0.001$ \\
\hline & & Boy & $0.48(0.00-1.28)$ & 100 & $<0.001$ & & \\
\hline & & Overall & $0.30(0.00-0.72)$ & 100 & $<0.001$ & & \\
\hline \multirow[t]{3}{*}{ Meat } & Processed meat & Girl & $0.18(0.09-0.27)$ & 99.3 & $<0.001$ & 48.88 & $<0.001$ \\
\hline & & Boy & $0.09(0.04-0.13)$ & 95.8 & $<0.001$ & & \\
\hline & & Overall & $0.14(0.09-0.18)$ & 98.9 & $<0.001$ & & \\
\hline \multirow[t]{15}{*}{ Milk \& dairy products } & Milk & Girl & $1.25(0.69-1.81)$ & 99.8 & $<0.001$ & 6.39 & 0.011 \\
\hline & & Boy & $0.38(0.00-1.11)$ & 99.9 & $<0.001$ & & \\
\hline & & Overall & $0.54(0.47-0.62)$ & 99.8 & $<0.001$ & & \\
\hline & Milk with added sugar & Girl & $0.18(0.09-0.28)$ & 97.8 & $<0.001$ & 24.16 & $<0.001$ \\
\hline & & Boy & $0.10(0.06-0.15)$ & 95.2 & $<0.001$ & & \\
\hline & & Overall & $0.15(0.10-0.19)$ & 97.1 & $<0.001$ & & \\
\hline & Yogurt & Girl & $0.98(0.47-1.50)$ & 99.7 & $<0.001$ & 1630.88 & $<0.001$ \\
\hline & & Boy & $0.92(0.00-2.45)$ & 99.6 & $<0.001$ & & \\
\hline & & Overall & $0.97(0.38-1.57)$ & 99.8 & $<0.001$ & & \\
\hline & Cheese & Girl & $0.61(0.55-0.68)$ & 82.2 & $<0.001$ & 5.69 & 0.017 \\
\hline & & Boy & $0.61(0.47-0.75)$ & 85.5 & $<0.001$ & & \\
\hline & & Overall & $0.61(0.56-0.65)$ & 83.0 & $<0.001$ & & \\
\hline & Ice cream & Girl & $0.57(0.40-0.74)$ & 99.7 & $<0.001$ & 93.54 & $<0.001$ \\
\hline & & Boy & $0.11(0.00-0.29)$ & 99.8 & $<0.001$ & & \\
\hline & & Overall & $0.32(0.23-0.40)$ & 99.7 & $<0.001$ & & \\
\hline \multirow[t]{22}{*}{ Miscellaneous } & Sugars \& sweets & Girl & $7.70(1.85-13.56)$ & 99.7 & $<0.001$ & 10.71 & 0.001 \\
\hline & & Boy & $4.32(0.00-11.39)$ & 99.8 & $<0.001$ & & \\
\hline & & Overall & $6.19(3.56-8.82)$ & 99.7 & $<0.001$ & & \\
\hline & Biscuits \& cakes & Girl & $4.01(0.00-8.07)$ & 99.8 & $<0.001$ & 0.10 & 0.750 \\
\hline & & Boy & $4.99(0.00-13.63)$ & 99.9 & $<0.001$ & & \\
\hline & & Overall & $4.20(3.52-4.89)$ & 99.8 & $<0.001$ & & \\
\hline & Jam & Girl & $1.49(0.76-2.23)$ & 95.7 & $<0.001$ & 0.72 & 0.395 \\
\hline & & Boy & $1.02(0.22-1.83)$ & 97.4 & $<0.001$ & & \\
\hline & & Overall & $1.27(0.87-1.67)$ & 95.4 & $<0.001$ & & \\
\hline & Puffs \& chips & Girl & $0.46(0.12-0.80)$ & 99.5 & $<0.001$ & 6.31 & 0.012 \\
\hline & & Boy & $0.29(0.00-0.59)$ & 99.5 & $<0.001$ & & \\
\hline & & Overall & $0.39(0.20-0.58)$ & 99.3 & $<0.001$ & & \\
\hline & Oil & Girl & $4.35(2.30-6.40)$ & 99.4 & $<0.001$ & 0.05 & 0.825 \\
\hline & & Boy & $2.40(0.00-5.48)$ & 99.8 & $<0.001$ & & \\
\hline & & Overall & $3.51(2.09-4.93)$ & 99.5 & $<0.001$ & & \\
\hline & Butter & Girl & $1.39(0.79-2.00)$ & 96.9 & $<0.001$ & 122.99 & $<0.001$ \\
\hline & & Boy & $0.38(0.00-0.89)$ & 97.7 & $<0.001$ & & \\
\hline & & Overall & $0.95(0.49-1.41)$ & 98.3 & $<0.001$ & & \\
\hline & Cream & Girl & $0.71(0.23-1.18)$ & 96.8 & $<0.001$ & 0.37 & 0.541 \\
\hline & & Boy & $0.34(0.18-0.51)$ & 81.1 & $<0.001$ & & \\
\hline & & Overall & $0.51(0.34-0.69)$ & 94.2 & $<0.001$ & & \\
\hline & Soft drink & Girl & $0.15(0.13-0.18)$ & 71.4 & $<0.001$ & 12.19 & $<0.001$ \\
\hline
\end{tabular}


Table 4 Results of sex subgroup analysis of daily servings of foods in Iranian children (concluded)

\begin{tabular}{|c|c|c|c|c|c|c|c|}
\hline Food group & Food item & $\begin{array}{l}\text { Subgroup } \\
\text { variable }\end{array}$ & $\begin{array}{l}\text { Daily serving intake } \\
\qquad(95 \% \mathrm{CI})\end{array}$ & $\mathrm{I}^{2}(\%)$ & $\mathbf{P}$ & $\begin{array}{l}\text { Interaction } \\
\text { test }\left(\chi^{2}\right)\end{array}$ & $\mathbf{P}$ \\
\hline & & Boy & $0.18(0.13-0.23)$ & 83.0 & $<0.001$ & & \\
\hline & & Overall & $0.16(0.14-0.18)$ & 82.4 & $<0.001$ & & \\
\hline & Coffee & Girl & $0.10(0.06-0.15)$ & 99.2 & $<0.001$ & 4.22 & 0.040 \\
\hline & & Boy & $0.03(0.00-0.07)$ & 99.6 & $<0.001$ & & \\
\hline & & Overall & $0.06(0.03-0.08)$ & 99.2 & $<0.001$ & & \\
\hline & Sauce & Girl & $2.70(0.44-4.97)$ & 99.2 & $<0.001$ & 17.46 & $<0.001$ \\
\hline & & Boy & $2.39(0.00-6.05)$ & 98.7 & $<0.001$ & & \\
\hline & & Overall & $2.39(0.00-6.05)$ & 98.8 & $<0.001$ & & \\
\hline
\end{tabular}

frequent (56). In another study, snacks (plum paste and fruit leather), fruit juice, and flavourings (tomato paste) were the top 3 food products being advertised during children's television programmes on 2 Iranian television channels (57). These finding endorse the necessity of developing restrictive policies on food marketing to children and monitoring their implementation (20).

There was a high level of heterogeneity in the present study, probably because of the limited number of studies and not having access to the data to find the heterogeneity sources. Future systematic reviews could benefit from focusing on the reasons behind such heterogeneity, including socioeconomic status, age, sex, nutritional literacy, parental educational level, and study setting. A study on Brazilian children has reported a higher intake of UPFs, such as cookies, pastries and sweet breads, and carbonated sugar-sweetened beverages among children of mothers with higher education levels (58). Also, children from higher-income households consumed more UPFs (59), while another study found that children from poorer backgrounds were significantly more likely to consume foods excessively high in calories, such as chips, fries, candies, and chocolate, at least once a week (60).

The overconsumption of energy-dense, nutrientpoor foods increases the risk of inadequate intake of nutrients needed by children $(59,61)$. A study on children aged 8-18 years in the United States of America showed that increased consumption of food items with low nutritional quality (i.e., sugar-sweetened beverages and candy) was associated with decreased intake of some vitamins (e.g., vitamin A and folic acid) and minerals (e.g., zinc, calcium and iron) (61).

In the present study, the meta-analysis by sex subgroups showed that girls had a higher intake of sugar and sweets, pasta, processed meat, milk, milk with added sugar, yogurt, ice cream, puffs and chips, butter, coffee, and sauce compared with boys, while consumption of soft drinks and pickles was higher in boys. There were no significant differences between the sexes in consumption of bread, cheese, jam, biscuits and cakes, oil, and cream. This result is partly inconsistent with a study in 1441 Bangladeshi adolescents who found that consumption of ready-to-eat/instant foods, sweets, confectioneries and similar packaged products, and sugar-sweetened beverages was significantly higher in boys than in girls (62).

This systematic review showed that there are limited data on PF intake by Iranian children according to their area of residence, and only 1 study has compared food consumption in rural and urban children (35). In urban children, the highest consumption of food items was related to sugar and sweets (11.78 daily servings vs 9.91 in rural children), while in rural children, consumption of oils was significantly higher than in their urban counterparts (5.35 vs 2.56 daily servings). This observation differs from that reported in Cambodia, where consumption of fats and oils in urban school children was higher than in rural children of all ages (63). A study in Indonesian children and adolescents showed a higher percentage of coffee consumption in rural areas, while those in urban areas had a higher consumption of sugar-sweetened beverages, caffeinated soft drinks and energy drinks, fatty fried foods, refined carbohydrates, and preserved meat (55).

Our study had several limitations. Firstly, the number of included studies was low. Meta-analysis for processed meat, processed fish, butter, cream and coffee was only performed on 3 studies and may had led to unreliable results. We did not exclude them due to their importance and significance. Therefore, further research needs to address the consumption of these foods in Iranian children. Secondly, we observed a considerable publication bias across the studies for certain food items (bread, milk, ice cream, soft drink, and puffs and chips). It is suggested that future studies examine the consumption of these food items in children. Thirdly, because of the small number of studies, we could not compare the consumption between study settings, school type, and socioeconomic and demographic subgroups. Fourthly, while the present study aimed to evaluate the consumption of PFs and UPFs in children aged 4-12 years, there was a lack of data on food consumption of children aged 4-5 years. Future studies need to pay particular attention to assessing food intake in this age group.

\section{Conclusion}

To our knowledge, this study is the first systematic review and meta-analysis to report consumption of PFs in 
Iranian children, and it has valuable data that can be useful for policy-makers regarding PF consumption in Iranian children. This study revealed that Iranian children are overconsuming PFs containing a high amount of sugar and/or fat. Improving their dietary habits requires pragmatic policies and tailored programmes to support a healthy food environment. Decreasing the dietary share of unhealthy PFs could substantially improve the nutritional quality of children's diets and contribute to the primary prevention of diet-related NCDs.

\section{Funding: None.}

Competing interests: None declared.

\section{Examen systématique et méta-analyse des aliments transformés/ultratransformés les plus couramment consommés par les enfants iraniens \\ Résumé}

Contexte : La tendance à l'augmentation du surpoids et de l'obésité chez les enfants représente une charge énorme pour les systèmes de santé. À cet égard, la disponibilité croissante d'aliments transformés, souvent riches en énergie et pauvres en nutriments, est devenue une préoccupation majeure. Pour inverser cette tendance, des politiques fondées sur des données factuelles sont nécessaires.

Objectifs : Le présent examen systématique visait à identifier les aliments transformés/ultratransformés les plus couramment consommés par les enfants iraniens âgés de 4 à 12 ans.

Méthodes : Nous avons effectué des recherches sur PubMed, Scopus et Web of Science, ainsi que sur des moteurs de recherche scientifiques en persan, notamment Iran Research Information System, Scientific Information Database et Mag-Iran. Nous avons également évalué la littérature grise, c'est-à-dire les études nationales et les documents présentés lors de congrès iraniens dans ce domaine. Toutes les données recueillies lors des études ont été converties en portions par jour. Les écarts types et moyens des résultats inclus ont été combinés en effectuant une méta-analyse à l'aide d'un modèle à effets aléatoires. Le test $\mathrm{I}^{2}$ a été utilisé pour calculer l'hétérogénéité. Le test d'Egger a servi à évaluer les biais de publication.

Résultats : Dix études portant sur 67093 enfants ont été incluses dans cet examen. La méta-analyse a démontré que la plus forte consommation d'aliments transformés correspondait au groupe des sucres et des produits sucrés avec 8,01 portions par jour, suivi des huiles, et des biscuits et gâteaux avec 5,58 portions par jour et 3,33 portions par jour, respectivement.

Conclusion : Compte tenu de la forte consommation d'aliments transformés peu sains, il est recommandé de mettre en place des politiques solides pour soutenir une alimentation saine et contribuer à améliorer l'environnement alimentaire des enfants iraniens.

$$
\text { الإير انيون اضاباشاهي، المنهجي و التحليل التلوي للأغذية المعالجَة/ الفائقة المعالجَة الأكثر شيوعًا التي يستهلكها الأطفال }
$$

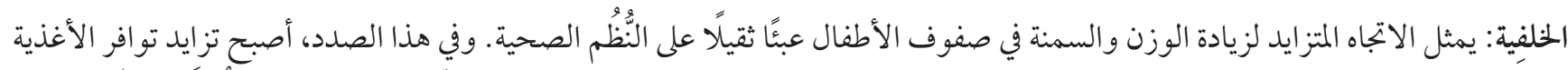

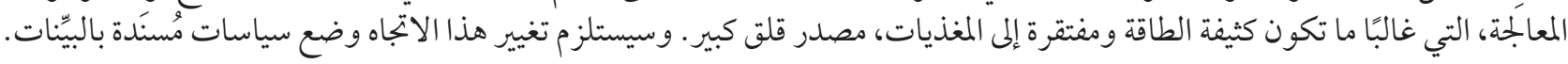
الأهداف: هدف هذا الاستعر اض المنهجي إلى تحديد الأغذية المعالَّة/ الفائقة المعالَكة الأكثر شيوعًا التي يستهلكها الأطفال الإيرانيون الذين تتراوح أعمارهم بين 4 أعوام و 12 عامًا.

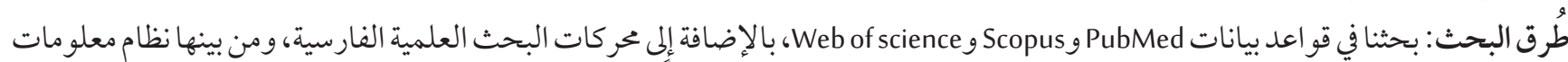

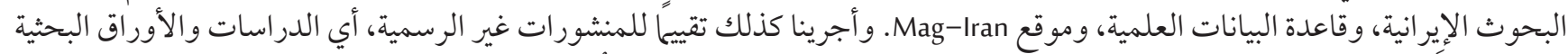

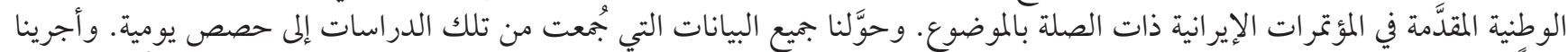

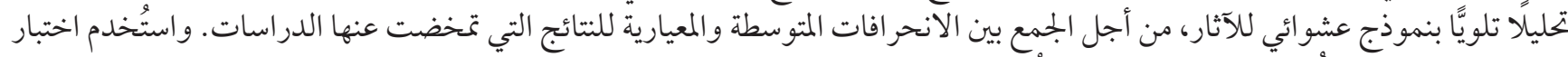

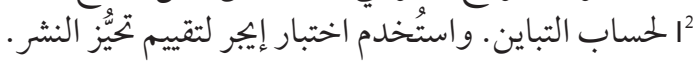

النتائج: شمل هذا الاستعراض عشر دراسات ضمَّت

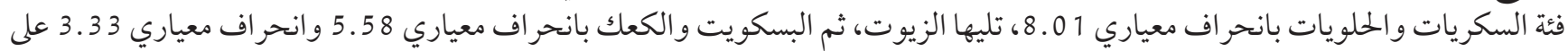


الاستناجات: نظرًا لارتفاع استهلاكك الأغذية المعالجَة المتدنية من الناحية الصحية، يُوصى باتباع سياسات قوية لدعم تناول الأغذية الصحية

$$
\text { والمساعدة على تحسين البيئة الغذائية للأطفال في إيران. لأنغان. }
$$

\section{References}

1. Bennett JE, Stevens GA, Mathers CD, Bonita R, Rehm J, Kruk ME, et al. NCD Countdown 2030: Worldwide Trends in non-communicable disease mortality and progress towards sustainable development goal target 3.4. Lancet. 2018 Sep 22;392(10152):107288. https://doi.org/10.1016/So140-6736(18)31992-5

2. Nugent R, Bertram MY, Jan S, Niessen LW, Sassi F, Jamison DT, et al. Investing in non-communicable disease prevention and management to advance the sustainable development goals. Lancet. 2018 May 19; 391(10134):2029-35. https://doi.org/10.1016/ So140-6736(18)30667-6

3. Farrag NS, Cheskin LJ, Farag MK. A systematic review of childhood obesity in the middle east and north Africa (MENA) region: prevalence and risk factors meta-analysis. Adv Pediatr Res. 2017; 4:8. https://doi.org/10.12715/apr.2017.4.8 PMID:29354689

4. Heidari-Beni M. Early life nutrition and non communicable disease. Adv Exp Med Biol. 2019;1121:33-40. https://doi. org/10.1007/978-3-030-10616-4_4A

5. Update on the commission on ending childhood obesity: report by the Director-General. Geneva: World Health Organization; 2015 (https://apps.who.int/iris/handle/10665/252837, accessed 25 May 2021).

6. Skinner AC, Ravanbakht SN, Skelton JA, Perrin EM, Armstrong SC. Prevalence of obesity and severe obesity in US children, 1999-2016. Pediatrics. 2018 Mar;141(3):e20173459. https://doi.org/10.1542/peds.2017-3459

7. Heidari-Beni M, Kelishadi R. Prevalence of weight disorders in Iranian children and adolescents. Arch Iran Med. 2019 Sep 1;22(9):511-5. PMID:31679373

8. Kelishadi R, Heidari-Beni M. Prevention and control of childhood obesity: the backbone in prevention of non communicable disease. Adv Exp Med Biol. 2019;1121:61-6. https://doi.org/10.1007/978-3-030-10616-4_7 PMID:31392653

9. Motlagh ME, Ziaodini H, Qorbani M, Taheri M, Aminaei T, Goodarzi A, et al. Methodology and early findings of the fifth survey of childhood and adolescence surveillance and prevention of adult noncommunicable disease: the CASPIAN-V study. Int J Prev Med. 2017 Jan 23; 8:4. https://doi.org/10.4103/2008-7802.198915 PMID:28217266

10. Goody J. Industrial food: towards the development of a world cuisine. In: Cooking, cuisine and class. A study in comparative sociology. Cambridge University Press; 2012:86-104.

11. Lerner A, Matthias T. Changes in intestinal tight junction permeability associated with industrial food additives explain the rising incidence of autoimmune disease. Autoimmun Rev. 2015 Jun;14(6):479-89. https://doi.org/10.1016/j.autrev.2015.01.009 PMID:25676324

12. Hawkes C, Chopra M, Friel S. Globalization, trade, and the nutrition transition. In: Labonte R, Schrecker T, Packer C, Runnels V, editors. Globalization and health: pathways, evidence and policy. New York: Routledge; 2009:257-84.

13. Canella DS, Levy RB, Martins APB, Claro RM, Moubarac J-C, Baraldi LG, et al. Ultra-processed food products and obesity in Brazilian households (2008-2009). PloS One. 2014 Mar 25; 9(3):e92752. https://doi.org/10.1371/journal.pone.0092752 PMID:24667658

14. Rauber F, Campagnolo P, Hoffman DJ, Vitolo MR. Consumption of ultra-processed food products and its effects on children's lipid profiles: a longitudinal study. Nutr Metab Cardiovasc Dis. 2015 Jan; 25(1):116-22. https://doi.org/10.1016/j.numecd.2014.08.001 PMID:25240690

15. Tavares LF, Fonseca SC, Rosa MLG, Yokoo EM. Relationship between ultra-processed foods and metabolic syndrome in adolescents from a Brazilian family doctor program. Public Health Nutr. 2012 Jan;15(1):82-7. https://doi.org/10.1017/S1368980011001571 PMID:21752314

16. Mallarino C, Gómez LF, González-Zapata L, Cadena Y, Parra DC. Advertising of ultra-processed foods and beverages: children as a vulnerable population. Rev Saude Publica. 2013 Oct;47(5):1006-10. https://doi.org/10.1590/s0034-8910.2013047004319 PMID:24626507

17. Khandpur N, Neri DA, Monteiro C, Mazur A, Frelut M-L, Boyland E, et al. Ultra-processed food consumption among the paediatric population: an overview and call to action from the European childhood obesity group. Ann Nutr Metab. 2020;76(2):109-13. https://doi.org/10.1159/000507840 PMID:32344405

18. Scaglioni S, De Cosmi V, Ciappolino V, Parazzini F, Brambilla P, Agostoni C. Factors influencing children's eating behaviours. Nutrients. 2018 May 31;10(6):706. https://doi.org/10.3390/nu10060706 PMID:29857549

19. Taillie LS, Busey E, Stoltze FM, Dillman Carpentier FR. Governmental policies to reduce unhealthy food marketing to children. Nutr Rev. 2019 Nov 1;77(11):787-816. https://doi.org/10.1093/nutrit/nuzo21 PMID:31329232

20. Abachizadeh K, Ostovar A, Pariani A, Raeisi A. Banning advertising unhealthy products and services in Iran: a one-decade experience. Risk Manag Healthc Policy. 2020 Jul 31;13:965-8. https://doi.org/10.2147/RMHP.S260265 PMID:32801970

21. The Islamic Revolution Assembly. The regulation on the establishment and monitoring of the work and activity of advertising centers. Ministry of Culture and Islamic Guidance; 1978.

22. Khodayari-Zarnaq R. Assessment of schools health activities and programs in the field of healthy diet and nutrition in Tabriz city in 2017. J Manag Strateg Health System. 2017;2(3):181-92. 
23. Yazdi-Feyzabadi V, Mohammadi NK, Omidvar N, Karimi-Shahanjarini A, Nedjat S, Rashidian A. Factors associated with unhealthy snacks consumption among adolescents in Iran's schools. Int J Health Policy Manag. 2017 Sep 1;6(9):519-28. https://doi. org/0.15171/ijhpm.2017.09 PMID:28949464

24. Babashahi M. Analysis of policies related to children's food environment (emphasizing on industrial food) in Iran in order to provide policy recommendations for child-friendly food environment [thesis]. Tehran: Shahid Beheshti University of Medical Sciences; 2021.

25. National guidelines for healthy nutrition canteen in schools. Tehran: Ministry of Health and Medical Education; 2017.

26. Iranian school milk program instructions executable. Tehran: National School Milk Committee; 2015.

27. Atashbahar O. Analyzing selected policies on optimal early childhood development to design policy solutions in Iran [thesis]. Tehran: Tehran University of Medical Sciences; 2019.

28. Sahargahi B, Ramezani P, Ghamarzad H. Problems of Iranian school milk program from the food and nutrition sciences experts' views. The First National Congress on Snack Foods. 30 April-1 May 2014, Mashhad, Iran.

29. Ahadi Z, Nabizadeh-Asl L, Akbari M, Mozaffari-Khosravi H, Nadjarzadeh A. Acceptance level of free milk program and the factors affecting on it in girl high schools in Yazd. Tolooebehdasht. 2013;12(3):140-8.

30. Liberati A, Altman DG, Tetzlaff J, Mulrow C, Gotzsche PC, Ioannidis JP, et al. The PRISMA statement for reporting systematic reviews and meta-analyses of studies that evaluate health care interventions: explanation and elaboration. BMJ. $2009 ; 339: b 2700$. https://doi.org/10.1136/bmj.b2700

31. European Food Safety Authority. Application of systematic review methodology to food and feed safety assessments to support decision making. EFSA Guidance for those carrying out systematic reviews. EFSA J. 2010; 8(6):1637. https://doi.org/10.2903/j. efsa.2010.1637

32. O'Connor A, Anderson K, Goodell C, Sargeant J. Conducting systematic reviews of intervention questions I: writing the review protocol, formulating the question and searching the literature. Zoonoses Public Health. 2014 Jun;61(Suppl 1):28-38. https://doi. org/10.1111/zph.12125 PMID:24905994

33. Jones JM. Food processing: criteria for dietary guidance and public health? Proc Nutr Soc. 2019 Feb;78(1):4-18. https://doi. org/10.1017/So029665118002513 PMID:30249309

34. Monteiro CA, Cannon G, Levy RB, Moubarac J-C, Louzada ML, Rauber F, et al. Ultra-processed Foods: what they are and how to identify them. Public Health Nutr. 2019 Apr;22(5):936-41. https://doi.org/10.1017/S1368980018003762 PMID:30744710

35. Weight disorder study. Tehran: Ministry of Health and Medical Education; 2012.

36. Stang A. Critical evaluation of the Newcastle-Ottawa scale for the assessment of the quality of nonrandomized studies in meta-analyses. Eur J Epidemiol. 2010 Sep;25(9):603-5. https://doi.org/10.1007/s10654-010-9491-z PMID:20652370

37. Moskalewicz A, Oremus M. No clear choice between Newcastle-Ottawa scale and appraisal tool for cross-sectional studies to assess methodological quality in cross-sectional studies of health-related quality of life and breast cancer. J Clin Epidemiol. 2020 Apr;120:94-103. https://doi.org/10.1016/j.jclinepi.2019.12.013 PMID:31866469

38. Food-based dietary guidelines - Iran. Rome: The Food and Agriculture Organization of the United Nations; 2020 (http://www.fao. org/nutrition/education/food-dietary-guidelines/regions/countries/iran/en/, accessed 26 May 2021).

39. Egger M, Smith GD, Schneider M, Minder C. Bias in meta-analysis detected by a simple, graphical test. BMJ. 1997 Sep 13;315(7109):629-34. https://doi.org/10.1136/bmj.315.7109.629 PMID:9310563

40. Alizadeh M, Mohtadinia J, Pourghasem-Gargari B, Esmaillzadeh A. Major dietary patterns among female adolescent girls of talaat intelligent guidance school, Tabriz, Iran. Iran Red Crescent Med J. 2012 Jul;14(7):436-41. PMID:22997560

41. Dadkhah piraghaj M, Amini M, Houshiar Rad A, Abdollahi M, Zoghi T, Eslami amirabadi M. Qualitative and quantitative dietary assessment of primary school children in Tehran. J Nutr Sci Food Technol. 2008 Spring;3(1):31-44.

42. Esfarjani F, Roustaee R, Mohammadi-Nasrabadi F, Esmaillzadeh A. Major dietary patterns in relation to stunting among children in Tehran, Iran. J Health Popul Nutr. 2013 Jun;31(2):202-10. https://doi.org/10.3329/jhpn.v31i2.16384 PMID:23930338

43. Amirhamidi Z. The association between eating behaviors and weight status in primary school students in the city of Tehran, 2015. Tehran: Shahid Beheshti University of Medical Sciences; 2017.

44. Ghiasvand R, Ashrafi M, Ashrafzadeh E, Asgari GR, Hasanzadeh A. [Relationship between junk foods intake and weight in 6-7 years old children, Shahin shahr and Meimeh, 1388]. J Health Syst Res. 2010; 6(2):335-43 (in Persian).

45. Mossaheb P, Kargar novin Z, Malek afzali B, Abadi A, Amini M. [The relationship between food intake and dental caries in a group of Iranian children in 2009]. J Res Dent Sci. 2011 Winter;7(4):42-50 (in Persian).

46. Oghli SS, Hidarnia A, Niknami S, Mohammadi SS, Jouybari T, Aghaei A. Adolescent girls eating behaviors about calcium-rich foods. Int J Trop Med. 2016;11(3):61-6. https://doi.org/10.36478/ijtmed.2016.61.66

47. Dorosty AR, Hodjat P. The study of some obesity associated factors in primary school girls. J School Public Health Inst Public Health Res. 2004 Summer;3 (2):25-35.

48. Pourhashemi SJ, Golestan B. Evaluation of the effect of consumption of sugars and carbonated drinks on anthropometric indices and dental health. J Dental School Beheshti Univ Med Sci. 2008 Fall;26(3):263-7.

49. Rezazadeh A, Damari B, Riazi-Esfahani S, Hajian M. Assessment of the situation and the cause of junk food consumption in Iranians: a qualitative study. Int J Nutr Food Eng. 2017; 11(9):521-4. 
50. The state of the world's children 2019. Children, food and nutrition: growing well in a changing world. New York: United Nations Children's Fund; 2019 (https://www.unicef.org/reports/state-of-worlds-children-2019, accessed 26 May 2021).

51. National diet and nutrition survey. Results from years 7-8 (combined) of the rolling programme (2014/15 to 2015/16). London: Public Health England and the Food Standards Agency; 2018 (https://www.gov.uk/government/statistics/ndns-results-fromyears-7-and-8-combined, accessed 26 May 2021).

52. Hawkes C, Harris J, Gillespie S. Changing diets: urbanization and the nutrition transition. In: 2017 global food policy report; Washington DC: International Food Policy Research Institute; 2017:34-41.

53. Marron-Ponce JA, Sánchez-Pimienta TG, da Costa Louzada ML, Batis C. Energy contribution of NOVA food groups and sociodemographic determinants of ultra-processed food consumption in the Mexican population. Public Health Nutr. 2018 Jan;21(1):8793. https://doi.org/10.1017/S1368980017002129 PMID:28937354

54. Blake CE, Wethington E, Farrell TJ, Bisogni CA, Devine CM. Behavioral contexts, food-choice coping strategies, and dietary quality of a multiethnic sample of employed parents. J Am Diet Assoc. 2011 Mar;111(3):401-7. https://doi.org/10.1016/j.jada.2010.11.012 PMID:21338739

55. Nurwanti E, Hadi H, Chang J-S, Chao JC-J, Paramashanti BA, Gittelsohn J, et al. Rural-urban differences in dietary behavior and obesity: results of the riskesdas study in 10-18-year-old Indonesian children and adolescents. Nutrients. 2019 Nov 18;11(11):2813. https://doi.org/10.3390/nu11112813 PMID:31752101

56. Amini M, Omidvar N, Yeatman H, Shariat-Jafari S, Eslami-Amirabadi M, Zahedirad M. Content analysis of food advertising in Iranian children's television programs. Int J Prev Med. 2014 Oct;5(10):1337. PMID:25400894

57. Hajizadehoghaz M, Amini M, Abdollahi A. Iranian television advertisement and children's food preferences. Int J Prev Med. 2016 Dec 15;7:128. https://doi.org/10.4103/2008-7802.195825 PMID:28105293

58. Sparrenberger K, Friedrich RR, Schiffner MD, Schuch I, Wagner MB. Ultra-processed food consumption in children from a basic health unit. J Pediatr (Rio J). 2015 Nov-Dec;91(6):535-42. https://doi.org/10.1016/j.jped.2015.01.007 PMID:26092227

59. Monteiro CA, Levy RB, Claro RM, de Castro IRR, Cannon G. Increasing consumption of ultra-processed foods and likely impact on human health: evidence from Brazil. Public Health Nutr. 2010 Jan;14(1):5-13. https://doi.org/10.1017/S1368980010003241 PMID:21211100

6o. Pabayo R, Spence JC, Casey L, Storey K. Food consumption patterns: in preschool children. Can J Diet Pract Res. 2012 Summer;73(2):66-71. https://doi.org/10.3148/73.2.2012.66 PMID:22668839

61. Kant AK. Reported consumption of low-nutrient-density foods by American children and adolescents: nutritional and health correlates, NHANES III, 1988 to 1994. Arch Pediatr Adolesc Med. 2003 Aug;157(8):789-96. https://doi.org/10.1001/archpedi.157.8.789 PMID:12912785

62. Islam MR. Exploring rural adolescents' dietary diversity, ultra-processed food consumption, and relevant socioeconomic correlates: a cross-sectional study from Matlab, Bangladesh [thesis]. Uppsala University; 2019.

63. Horiuchi Y, Kusama K, Kanha S, Yoshiike N, Team FR. Urban-rural differences in nutritional status and dietary intakes of school-aged children in Cambodia. Nutrients. 2018 Dec 20:11(1):14. https://doi.org/10.3390/nu11010014 PMID:30577546 